\title{
Guided Goal Setting in Therapy Towards Being Fully Functioning
}

\author{
Susan Renger ${ }^{1}\left[\right.$ ] Ann Macaskill ${ }^{1}[$
}

Accepted: 22 April 2021 / Published online: 11 May 2021

(c) The Author(s) 2021

\begin{abstract}
This qualitative study considered whether the provision of a framework of potential goals based on Rogers' idea of the fully functioning person would be of any benefit to therapy clients in their goal setting process. It also considered addressed whether client goal setting was methodologically acceptable to integrative therapists who used Rogers' non-directive principles as the foundation to their approach. We provided a goal setting instrument to 9 therapists and 23 of their clients, enabling them to define therapy goals, and feedback on the process. The clients set their goals using the instruments, before having at least six sessions with their therapist. We then sought joint views on the process from the therapists through a questionnaire or an interview. The data from the responses were analyzed using Thematic Analysis. The majority of the therapists considered that guided goal setting using a description of the 'fully functioning' individual was helpful. In terms of the applicability of goal setting to an integrative approach based on non-directive, person-centered principles, the results were mixed and in some cases contrary to those expected. For example, some of the more directive therapists disliked guided goal setting processes, whilst the more non-directive therapists appreciated the approach.
\end{abstract}

Keywords Person-centered $\cdot$ Therapy $\cdot$ Goal setting $\cdot$ Fully functioning $\cdot$ Self-counseling

Goal setting is a commonly used therapeutic process, seen originally in Bordin's notion of the goals, tasks and bond features of therapy (1979). Many therapeutic approaches now use collaborative goal setting, and many studies have demonstrated the effectiveness of goal setting on behavior change (e.g. Epton et al., 2017). Specifically, Lewis et al. (2017) for example, discuss the importance of setting measurable goals within Motivational Interviewing, and Archuleta et al. (2020) have demonstrated the effectiveness of the technique in Solution-focused Therapy. Physical therapy approaches also use the technique, as Melin et al. (2019) have shown in their study on person-centered goal setting in physiotherapy, for example. Given a widespread acceptance that goals assist therapeutic processes, the research agenda has turned more recently to the way in which goal setting can best be managed. For example, the clarity of the goals set is regarded as important, with Geurtzen et al. (2020) reporting that clients who said that their goals were unclear found the

Susan Renger

sue@suerenger.co.uk

1 Centre for Behavioural Science and Applied Psychology, Social and Economic Research Institute, Sheffield Hallam University, Howard St, Sheffield S1 2WB, UK therapeutic alliance to be reduced, they reported their symptom levels to be higher, and had a greater need for future sessions. The process used to define goals is also seen as significant, with a collaborative approach being preferred: In their meta-analysis of studies of goal consensus and collaboration across therapeutic orientations, Tryon et al. (2018) concluded that when therapists and their clients agree on psychotherapy goals and actively collaborate, they tend to have more positive treatment outcomes.

Consistent with a more person-centered focus on patient care in health settings, Jacob et al. (2017) note the need for personalized outcomes in psychotherapy in order for care to be tailored to the client, but that existing outcome measures do not facilitate that process. They conclude their study with young people, suggesting that new measures are needed that capture some of the idiosyncratic goals that clients may have. The personalization of goals is now firmly on the agenda for therapists, and there are a number of recent studies shedding light on a possible way forward. For example, the type of goals that clients work with are considered to affect therapeutic outcomes. Katz et al. (2015) present findings suggesting that clients may be better motivated through value promotion goals, rather than symptom prevention goals. Lindheim et al. (2016) also suggest that 
psychotherapy is more effective when goals are individually defined rather than designed around broad measures of problematic symptoms. This person-centered focus, where clients are encouraged to establish their own individual outcomes is increasingly being seen as a preferred approach to goal definition. It is understandable that goal setting has been based on standardized outcome measures in order to assist in efficacy research, but as Lloyd et al. (2019) conclude in their systematic review, goal-focused measures that are idiographic may better facilitate client progress in contrast to nomothetic measures. An even greater depth of analysis of client goals is considered relevant to progress by Roch et al. (2017) who suggest that individuals' implicit motives should be considered when personal goals are discussed during therapy.

One facet of goal definition that seems to be commonly accepted, is that goals should imply forward movement rather than simply avoiding negative affect. Further, Oddli et al. (2021) found that future-oriented activity in therapy facilitated goal attainment, in that the therapist comes alongside the client in the movement towards their goal. In fact Cooper (2019) considers that directionality is the key to client agency and the self-actualizing quality of the human being.

However, clients are not always able to articulate their goals for therapy easily, particularly being used to the problem focus of exiting outcome measures, coupled with a desire to simply stop suffering. Further, when therapists were questioned on what they regarded as a good outcome for their clients, they were largely unable to articulate it (Renger et al., 2020). An ideal start point to define openended idiosyncratic goals would be Rogers' notion of the fully functioning individual who would have, for example; an increasing openness to experience, and be moving towards increasingly existential living (Rogers, 1967). However, these are broad concepts from which concrete goals are not easily derived. Also, Rogers saw self-actualization as a process and not and endpoint, making achievable goals difficult to define.

We therefore offer a new perspective for goal setting for this study, aligned with the idea of humanistic self-actualization, using a detailed description of the fully functioning person (Renger \& Macaskill, 2021a).

Goal setting based on the idea of a fully functioning person within most therapeutic approaches is not inherently problematic, since they incorporate some degree of directivity on the part of the therapist. Person-centered therapists on the other hand have always rejected the idea of directing anything in the therapeutic process. However, Cooper and Law (2018) suggest specifically, that person-centered therapists should orientate their processes towards their clients' goals. Grey et al. (2018) also support the approach, considering that humanistic therapy can be enhanced through goal setting. Goal setting in non-directive therapies is however, a methodological paradox and is only just beginning to emerge as an acceptable approach. Accordingly, research literature is limited.

However, the psychotherapy landscape is changing. Pure approaches to psychotherapy are giving way to more integrative methodologies. Common factors such as the therapeutic alliance, empathy, goal consensus and collaboration, positive regard and congruence are now considered better predictors of a positive outcome in therapy than therapist allegiances (Nahum et al., 2019). In fact Rief (2021) recommends that the training of psychotherapists should switch from focusing on theoretical frameworks to learning key competencies, one of which is the clarification of client motives and goals. This study therefore aims to establish whether goal setting can be applicable to a person-centered approach where it is used as the foundation to integrate a range of therapeutic methodologies.

This study had two aims, firstly to assess the usefulness of a framework of therapy goals based on Rogers' notion of the fully functioning person to guide client's goal setting, and secondly to establish whether client goal setting is considered acceptable to integrative therapists who use person-centered principles as the foundation to their approach. In order to ground the debate in clinical practice, these concepts were addressed by therapists and their clients in therapy using a choice of two goal setting instruments. The outcomes for the study could be of interest to therapists who wish to utilize the process of goal setting to greater effect in their therapy, particularly where there are a limited number of sessions available and they need to focus therapeutic engagement. Further, clients may find the goal setting instruments useful in preparing for their therapy or to use in on-going development post therapy.

\section{Methodology}

We approached this qualitative study from a Critical Realist perspective (Bhaskar, 2016), which is explained by $D_{r} \geq D_{a} \geq D_{e}$, where $D$ is the domain and $r$, a, and e are real, actual and empirical perspectives (Collier, 1994). We sought to test the generative mechanisms considered to underlie goal setting processes in therapy, or what causes $\mathrm{D}_{\mathrm{r}}=\mathrm{D}_{\mathrm{a}}=\mathrm{D}_{\mathrm{e}}$. In essence, in this qualitative study, a distinction is made between the event and what causes it. Firstly, conditions necessary for the observable event are created i.e. facilitated goal setting, and secondly, results caused by underlying laws and mechanisms which are unobservable are considered. Given that multiple paradigms are considered feasible within one study (Teddlie \& Tashakkori, 2009), we also took a pragmatic perspective. We used the traditional perspective of methodological pragmatism (Morgan, 2014) 
here, which advocates that whatever methods produce the optimum results should be considered. Therefore the study was designed with an emphasis on the practical application of theory in an experimental setting.

The research strategy most often associated with Critical Realism is that of retroductive reasoning (Blaikie, 2007), although an argument is put forward by Meyer and Lunnay (2013) that a combination of both retroductive and abductive reasoning is most useful. On this basis, we used both perspectives in the process of data analysis in this study.

Finally, a degree of phronesis, or 'practical wisdom', was also necessary in designing the study and analyzing the responses. The innate knowledge brought to this study and the motivation to conduct it derives from the following: The first researcher has qualifications and experience in education and training coupled with experience and qualifications in person-centered therapy. The second researcher is trained in both person-centered therapy and Cognitive Behavioral Therapy and conducts high level university research. The researchers therefore bring a learning facilitation perspective to therapy research and a belief that learning can be goal focused and can be applied to client-centered therapy. Sheffield Hallam University (UK) Research Ethics Committee reviewed the study and approved it.

\section{Method}

From a pragmatic perspective, we needed to design an intervention in which therapists would be able to test out goal setting with their clients. Since it is not possible to isolate cause and effect conclusively (as a closed system experiment would require), we designed a qualitative experiment (Kleining, 1986). This is a research method dating back to 1905 which was used originally to test learning processes using an experimental attitude. It is an exploratory, heuristic form of experimentation, which manipulates a social or psychological situation in order to research the structures and processes involved. Qualitative experiments may be started with a rather vague assumption of the outcome and then confront participants with a particular task and observe what happens (Kleining \& Witt, 2001). The research situation is open and changes as the research progresses, i.e. variables are not controlled as in a standard experiment. Indeed the relationship between the experimenter and the participant contributes to the outcomes.

\section{Participants}

We used a purposive sampling strategy, inviting therapists by direct email using the British Association of Counselling and Psychotherapy database of practitioners, and in person from a UK based counseling charity. We selected participants who described themselves as integrative, but with the person-centered core conditions as their foundation. We excluded any students or counselors who were in their first year of practice. In total, nine therapists agreed to participate, 6 of whom were female and 3 were male. All were white British, other than one who described herself as black British. None of the therapists worked together or knew each other. One of the therapists was an acquaintance of one of the researchers. A phone call was made to explain the purpose of the study and information sheets and consent forms sent by email. The subsequent client recruitment process can be defined by a 'snowball' sampling strategy in that the therapists then engaged their own clients in the study. The numbers of clients recruited by the therapists differed as follows; 3, 9, 2, 1, 3, 1, 1, 2, 1. Identifying data for the clients was retained by the therapist to maintain confidentiality. Consent forms were completed by the therapists and returned, but consent to participate by the clients was obtained verbally by the therapists.

\section{Materials}

Rogers' notion of the fully functioning person has been described in a taxonomy of 71 elements (Renger \& Macaskill, 2021a) such as; 'I can accept the things in my life that I can't control' and 'I can rely on myself' with the intent to provide a start point for client's thinking about their own therapy goals. This description of the fully functioning person is lengthy, so we designed an exercise which would present the client with only one or two of these elements at a time, from which they could derive their own goals. This was achieved by presenting the list of elements in the form of a card sort exercise which works like a decision tree. This format enabled the client to choose firstly between 8 topics, then a small number of subtopics and finally a small number of elements. The client would then further define their own goal based on the suggested element. We also produced a full questionnaire for clients who may think more holistically, therefore allowing the client to examine each element in turn and then develop suitable goals as necessary. Finally, we produced a learning plan which was a form on which clients could record and assess progress on their personal goals. We intended that clients would be able to adapt and work on the goals both during and after therapy. Goals could also be readdressed and changed over time to allow for changes in the client's self-perception.

\section{Procedure}

We briefed the therapists on the use of the instruments indicating that they could be used at any time in the therapy process and at any time in a session, although we envisaged that the start of therapy might be appropriate. We also suggested 
that the therapists should seek informal feedback from their clients before they gave their own feedback at the end of the study. We conducted semi-structured interviews to gather feedback once the clients had completed their 6 sessions. Six therapists opted to provide a written response, and three therapists preferred a telephone interview, in which case, we transcribed their answers. We asked whether the guided goal setting had been beneficial to the therapeutic process, and how the therapists had each managed the exercise. We enquired at what stage in the therapy goal setting seemed to be most useful, and how the clients had experienced the process. Finally, we enquired whether the idea of goal setting fitted with the therapist's particular style of therapy.

\section{Data Analysis}

The analytical strategy for the data followed the guidelines for Thematic Analysis (TA) (Braun \& Clarke, 2006). We opted for this approach in order to scrutinize affective indepth experiencing and phenomenological expressions, in addition to more positivist comments. Further, the considerable flexibility provided by this approach to the analysis of cognitive and affective elements, whether constructivist or reductionist, made it an ideal tool for addressing the complex issue of goals in therapy. Finally, the flexible nature of Thematic Analysis allowed for the manipulation of data in relatively subjective ways, facilitating the researcher's interpretation of the wide range of opinions. (This subjective process is seen as a positive advantage in the context of Thematic Analysis rather than a negative source of bias.) There are six stages in the process; becoming familiar with the data, identifying and generating initial codes, searching for themes, reviewing the themes, and defining the themes.

The initial analysis by the first author, was conducted using the Critical Realist perspective of 3 levels of analysis. Firstly, what was actually said by the respondents was analyzed at a semantic level, clarifying any complex statements into summaries, and then inferences made about the meaning behind the participants' comments. Then, using a combination of both retroductive and abductive reasoning, inferences about causal mechanisms were made. The abductive element of the process sought to highlight data which did not match with the researcher's understanding of the subject and thus provided new insights into the topic of goal setting. The transcripts were coded and recoded in their entirety with many comments being coded into more than one category. Pragmatically, a template was brought to the analysis based on the original research questions, which facilitated the collation of the codes into themes. For quality assurance, the second author reviewed the transcripts and the emergent themes for any disparities in interpretation, which were then discussed and resolved. A third therapist/ researcher reviewed and contributed amendments to the final analysis.

\section{Results}

The therapists made their own decisions about which instrument to use and when to use it. Therapists $\mathrm{T} 4$ and $\mathrm{T} 1$ used the questionnaire only, therapist $\mathrm{T} 5$ used only the cards, and the rest of the therapists tried both instruments with different clients, or in one case, both with one client. There were a mix of responses to the idea of a structured goal setting process from the therapists. Some of the therapists who fundamentally struggled with the idea of goal setting disengaged with the approach. They found the process unhelpful, saying that they couldn't see themselves continuing to use the instruments again (e.g. T9). However, those therapists who had commented positively on the process of goal setting, cited benefits from the structure that the instruments brought: One mentioned the greater autonomy and sense of control experienced by the client (T3), and the benefit of having a framework/structure through which the client could start to think about their goals (T6). The main benefit however, seemed to be that clients discovered new areas of focus (e.g. T2), that they may not have previously considered. Several reported that the goal setting seemed to benefit some clients in particular, especially those familiar with a cognitive behavioral approach.

The therapists had also been asked to capture the responses of their clients to the goal setting process. A variety of reactions to the instruments were reported, with some clients seemingly gaining a lot from the experience, and others being unwilling to engage at all. For example, one client seemed to engage in depth with the process (T1); another found it suited their way of thinking and working (T3); and some seemed to welcome an opportunity to refocus (T5). Other comments demonstrated negative results as clients were reported not to have taken to it (T8). Further, the formal nature of the process jarred with $\mathrm{T} 7$ who felt that questionnaires frightened his clients. Interestingly, T3 reported having a client who agreed to goal setting but then didn't want to discuss what they had done. Finally, it was clear that some clients may not have engaged with the goal setting process, but comments by therapists indicated a possible cause. For example, T9 suggested that he may have 'chickened out' of the process and $\mathrm{T} 8$ thought that their lack of structure was the barrier.

The therapists were also asked about how they conducted the goal setting process. Six therapists engaged in collaborative goal setting with their clients, using either or both of the instruments. These six therapists explained the materials mostly in session, suggesting the client either work with them in therapy or take them home and work through them 
in more detail on their own. Alternatively, the materials were handed over by three therapists without a detailed explanation, allowing the client to use the instruments independently as they saw fit. In the event, more positive responses for the usefulness and likely further use of the instruments were given by those therapists who engaged in the process with their clients.

Suggestions also emerged on which types of client might benefit most from the process of goal setting. Views ranged from clients who are calm and focused, to Cognitive Behavioral Therapy type clients, or those who may be struggling with life issues such as a crisis of meaning, a midlife crisis, or an 'empty nest' (T6). No consistent view emerged on this topic, other than a suitability for clients who were more goal oriented, or those who would benefit from the encouragement of self-directivity.

Goal setting had been introduced to clients at various points in the process of their therapy which provided some interesting feedback that had not been anticipated prior to the study. Three therapists worked on client goals early in the therapeutic process. Other clients were mid-way through their therapy when they considered their goals. The therapist who found goal setting to be the most useful, completed the process for two clients after session numbers 112 and 161 respectively. One participant found the goal setting process useful at the end of therapy to plan a way forward with their client, whilst T4 found it was helpful to refer back to the goals as therapy progressed. Some considered that they wouldn't set goals right at the start of therapy, and T1 suggested that they should be used when someone is in a calmer state having talked through their immediate concerns.

Finally, the therapists were asked initially to consider whether the idea of goal setting was compatible with their perspective on therapy. Unexpectedly, the most positive responses emerged from therapists who described themselves as the most person-centered (T1:85\% and T2:80\%), whilst the most negative reception came from T9 who described himself as $60-75 \%$ person-centered. T9 said for example, that they felt it would have been slightly disrespectful to guide the goal setting process. Another counsellor (T6), describing himself as less person-centered noticed a discomfort with a more directive way of working. Further, a more directive counsellor suggested that with one client, the dynamics of the relationship shifted (T3). However T1, described as $85 \%$ person-centered, found that it allowed new goals to emerge, and $\mathrm{T} 2$ considered that the process helped in all 3 of their client cases despite preferring an $80 \%$ person-centered approach. In summary, the therapists' views on directivity did not correlate with their views on goal setting. Ultimately however, no consistent view emerged on the appropriateness of goal setting where person-centered principles were foundational, with a range of responses offered. For example, on the negative side, $\mathrm{T} 7$ thought it took it away from their 'flowing' and T8 considered the whole process to be too cumbersome, taking away from the skill of the therapist. Then other comments were more positive, noticing how focused the client became, and that the collaborative process enabled them to explore areas of client interest in depth.

\section{Discussion}

Personalized goal setting is beginning to take precedence over using standardized measures to guide therapy and measure efficacy, giving the client a greater degree of control over their progress. Rodgers (2017) for example, examines the numerous methodological, socio-political and technical problems associated with commonly used outcome measures and suggest that a new focus on personalized instruments would allow for a measurement process that contributes to the client's process of recovery. In their review of patientcentered assessment in psychotherapy, Sales and Alves (2016) identified a range of individualized tools which allow for idiographic rather than nomothetic measures. However, the personalized goal setting tools largely rely on the client to generate their own goals based on the problems that have brought them to therapy. In fact, the clients in our study also reported that they had an expectation that they would focus on what was problematic for them. Current tools therefore do not facilitate goals that are holistic, open ended, positive and growthful.

Rogers' views on person-centered learning facilitation with his university students provides an interesting insight into his experience of goal setting. Given the anxiety that arose when he gave them the opportunity to define their own curriculum from a blank sheet, he decided to give them some structure in the form of suggested topics (Rogers, 1969). Although the idea of the fully functioning person was outlined only broadly by Rogers, he did suggest that this optimal endpoint of therapy might eventually be further defined and operationalized. Our instruments for this study therefore present a detailed description of a fully functioning person to be used to initiate a forward focused goal definition process with the client. After some clarification, the elements contained in the framework were largely accepted by the participants as a positive and forward focused aid to setting client goals.

It seemed that therapists who bought into the process of goal setting enabled it to work, whilst some who were less convinced that directivity was appropriate, were less happy to immerse themselves fully in the process. Of those who did engage in the process, most felt that therapeutic benefit was likely to be achieved from working with the client on their goals. As Di Malta et al. (2019) suggest, a collaborative therapeutic relationship is important in enabling the process of goal setting. It seemed here that as the client worked 
with the therapist to define goals which were concrete and motivational, something more was achieved than may otherwise have been generated from self-reflection alone, (see Tryon et al., 2018). And as McLeod and Mackrill (2018) suggest, many clients find it hard to define what they want from therapy without support, so either the discussion, or the fully functioning items were able to provide the guidance necessary.

The clients in the study also had mixed views about the benefit of setting goals as part of their therapeutic process. In fact, some clients did not engage with the goal setting process in any meaningful way. It seemed here, that the therapists may have affected the clients' views on goal setting based on their own level of comfort with the process. Cooper and Law (2018) suggest that around six out of ten people would like goals in therapy, two out of ten would not, and two out of ten are ambivalent. This therefore begs the question of whether clients may have a greater preference for goal setting than therapists are willing to acknowledge.

Cooper and Law (2018) also suggest that goals and goalrelated processes relate closely to how positive people feel. Moving towards attainable goals and then achieving them is associated with positive affect and a sense of well-being. This may explain why some clients did find motivation in the exercise. Further, some of the clients did the exercise on their own, and did not share what they had done with their therapist. It could be that where activities of this type are self-initiated, a sense of empowerment gives rise to a feeling of freedom from being monitored by an authority figure, which then results in a sense of self-efficacy. For example, Moore et al. (2020) found that autonomous motivation is central to goal progress, particularly with high achievers, so it may be that these clients appreciated the sense of selfmastery and autonomy that working alone gave them.

The methodological integrity of integrative and pluralistic approaches to therapy that utilize Rogers' core conditions is not readily accepted by everyone. For example, Ong et al. (2020) suggest that ontological eclecticism is basically incompatible with the person-centered approach. Accordingly, there were advocates of this view who proved to be very uncomfortable with a directive goal setting process in this study. In fact, Holdstock and Rogers (1983), claim that the person-centered approach does not exclude the use of techniques as long as they are not forced on the client. From this more contemporary perspective of person-centered therapy, some of the study participants readily accepted a tentatively directive approach. What was unanticipated however, was that those therapists regarding themselves as more person-centered, were more likely to support this directive methodology.

Some of the incompatibility arguments around goal setting processes based on person-centred principles could be overcome when therapy is considered from the perspective of a learning process (Renger \& Macaskill, 2021b). Rogers considered that learning facilitation was appropriate in the counseling relationship, in the sense that a process of self-learning and therapeutic change are facilitated (Rogers, 1969). And further, his theory of personality and behavior (Rogers, 1952) describes the goal-oriented organism attempting to satisfy its needs, as foundational to the approach. One of the fundamental features of a self-directed learning process is that of goal setting (see Hematian et al., 2017). It may be therefore, that if the person-centered therapy process is regarded as inextricably linked to the process of learning, then the formulation of a sense of direction, or of ideal goals could also be methodologically applied to therapy based on person-centred principles.

\section{Limitations}

There were a number of limitations associated with this study. For example, each therapist was asked to recruit six clients. However, due to sickness and client recruitment issues, fewer clients were involved than we had anticipated, which limited the breadth of data collected. Further, one therapist had a large proportion of the clients skewing the results. The therapist-client relationship and the therapists' beliefs would undoubtedly have added a bias to the results of the study and a great deal more information on these areas could certainly have been sought to add depth to the study results. The therapists had committed to a more robust data collection process from their clients than they enacted. In the event, the feedback was much more anecdotal and represented mostly the therapist's experience of the instruments rather than the client's experience. Finally, no claim could be made that the sample of clients or their therapists represented any degree of cultural diversity. Neither could it be claimed that UK integrative therapists are representative of those from different countries with different therapeutic traditions. The study used a complex design on a methodological basis of Critical Realism and pragmatism. Further, the idea of a qualitative experiment is not commonly used for research in this field. Additionally, the specific background that the first researcher brought to the study, was that of a learning/development professional and a counselor. Therefore, it would be difficult to replicate the study design with any degree of accuracy. The study originally had been designed to obtain detailed information from the clients. However, the therapists involved considered that it would be unethical to breach client/therapist confidentiality by even identifying who their clients were. Neither were the therapists willing to formally interview their clients, or record any feedback. We therefore we able to gain client responses only via the therapists. Finally, the study used only a small sample of therapists and their clients over a short period of 
time, and fairly broad based questions were used. To explore the subject fully, the questions would need to be addressed in much greater depth with more participants.

\section{Conclusion}

This study was designed to establish whether a group of integrative therapists, who used person-centered principles as the foundation to their approach, considered guided goal setting, on the basis of a description of the fully functioning person, to be a useful process. It also sought to establish how these therapists managed the goal setting process and whether they considered it methodologically acceptable within their therapeutic approach. The majority of the therapists found guided goal setting to be a useful therapeutic process, and further that having the structure of an 'ideal' outcome for therapy was a useful start point from which clients could form their own idiosyncratic and growthful goals. The goal setting process seemed to function better as a collaborative endeavor, it was used effectively at different points in the therapy journey, and worked at varying degrees of depth. Some of the therapists who were more directive, surprisingly were less comfortable with directing the goal setting process, but the majority of therapists considered it a suitable approach to an integrative style of therapy that used person-centered principles at its core.

Whilst the use of therapy goals is a subject that has been addressed in a variety of therapeutic approaches, the application of the approach to therapy based on non-directive principles is still uncommon and less well researched. Research into the use of outcome measurement tools that are based on personalized goals is also limited and a relatively new concept in the field. We consider therefore that this study would benefit from being repeated with a much larger sample of therapists with a more detailed experimental framework. Specifically, more attention could be given to establishing whether a process which guides the client towards personalized fully functioning goals is preferable to starting with a blank sheet, or to using standardized symptom focused measures that may be applicable to the majority.

Funding No funding was received for conducting this study.

Data Availability Supporting data is available from the corresponding author.

\section{Declarations}

Conflict of interest The authors have no relevant financial or non-financial interests to disclose.
Ethics Approval Approval was obtained from the ethics committee of Sheffield Hallam University, UK.

Informed Consent Informed consent was obtained from all individual participants included in the study. Participants gave informed consent regarding publishing their data.

Open Access This article is licensed under a Creative Commons Attribution 4.0 International License, which permits use, sharing, adaptation, distribution and reproduction in any medium or format, as long as you give appropriate credit to the original author(s) and the source, provide a link to the Creative Commons licence, and indicate if changes were made. The images or other third party material in this article are included in the article's Creative Commons licence, unless indicated otherwise in a credit line to the material. If material is not included in the article's Creative Commons licence and your intended use is not permitted by statutory regulation or exceeds the permitted use, you will need to obtain permission directly from the copyright holder. To view a copy of this licence, visit http://creativecommons.org/licenses/by/4.0/.

\section{References}

Archuleta, K. L., Mielitz, K. S., Jayne, D., \& Le, V. (2020). Financial goal setting, financial anxiety, and solution-focused financial therapy (SFFT): A quasi-experimental outcome study. Contemporary Family Therapy, 42(1), 68-76.

Bhaskar, R. (2016). Enlightened common sense: The philosophy of critical realism. Routledge.

Blaikie, N. W. H. (2007). Approaches to social enquiry: Advancing knowledge. (2nd ed.). Polity.

Bordin, E. S. (1979). The generalizability of the psychoanalytic concept of the working alliance. Psychotherapy: Theory, Research \& Practice, 16(3), 252-260.

Braun, V., \& Clarke, V. (2006). Using thematic analysis in psychology. Qualitative Research in Psychology, 3(2), 77-101.

Collier, A., \& Bhaskar, R. (1994). Critical Realism: An introduction to Roy Bhaskar's philosophy. Verso.

Cooper, M. (2019). Directionality: A Rosetta Stone for psychotherapy. https://www.psychotherapyexcellence.com/Blog/2019/March/ Directionality-A-Rosetta-Stone-for-Psychotherapy.

Cooper, M., \& Law, D. (Eds.). (2018). Working with goals in psychotherapy and counselling. Oxford University Press.

Di Malta, G. S., Oddli, H. W., \& Cooper, M. (2019). From intention to action: A mixed methods study of clients' experiences of goal-oriented practices. Journal of Clinical Psychology, 75, 1770-1789. https://doi.org/10.1002/jclp.22821.

Epton, T., Currie, S., \& Armitage, C. J. (2017). Unique effects of setting goals on behavior change: Systematic review and metaanalysis. Journal of Consulting and Clinical Psychology, 85(12), 1182-1198. https://doi.org/10.1037/ccp000026.

Geurtzen, N., Keijsers, G. P., Karremans, J. C. T., Tiemens, B., \& Hutschemaekers, G. J. (2020). Patients' perceived lack of goal clarity in psychological treatments: Scale development and negative correlates. Clinical Psychology and Psychotherapy, 27(6), 915-924. https://doi.org/10.1002/cpp.2479.

Grey, N., Byrne, S., Taylor, T., Shmueli, A., Troupp, C., Stratton, P., Sefi, A., Law, R., \& Cooper, M. (2018). Goal-oriented practice across therapies. In M. Cooper \& D. Law (Eds.), Working with goals in psychotherapy and counselling. Oxford University Press.

Hematian, F., Rezaei, A. M., \& Mohammadyfar, M. A. (2017). On the effect of goal setting on self-directed learning, achievement 
motivation, and academic achievement among students. Modern Applied Science, 11(1), 37-47.

Holdstock, T. L., \& Rogers, C. R. (1983). Person-centered theory. In R. J. Corsini \& A. J. Marsella (Eds.), Personality theories, research \& assessment.FE Peacock Pub.

Jacob, J., Edbrooke-Childs, J., Law, D., \& Wolpert, M. (2017). Measuring what matters to patients: Using goal content to inform measure choice and development. Clinical Child Psychology and Psychiatry, 22(2), 170-186.

Katz, B. A., Catane, S., \& Yovel, I. (2015). Pushed by symptoms, pulled by values: Promotion goals increase motivation in therapeutic tasks. Behavior Therapy, 47(2), 239-247. https://doi.org/ 10.1016/j.beth.2015.11.002.

Kleining, G. (1986). Das qualitative experiment. Kölner Zeitschrift für Soziologie und Sozialpsychologie, 38(4), 724-750.

Kleining, G., \& Witt, H. (2001). Discovery as basic methodology of qualitative and quantitative research. Forum Qualitative Sozialforschung/Forum: Qualitative Social Research, 2(1).

Lewis, T. F., Larson, M. F., \& Korcuska, J. S. (2017). Strengthening the planning process of motivational interviewing using goal attainment scaling. Journal of Mental Health Counseling, 39(3), 195-210. https://doi.org/10.17744/mehc.39.3.02.

Lindhiem, O., Bennett, C. B., Orimoto, T. E., \& Kolko, D. J. (2016). A meta-analysis of personalized treatment goals in psychotherapy: A preliminary report and call for more studies. Clinical Psychology: Science and Practice, 23(2), 165-176.

Lloyd, C. E., Duncan, C., \& Cooper, M. (2019). Goal measures for psychotherapy: A systematic review of self-report, idiographic instruments. Clinical Psychology: Science and Practice, 26(3), e12281.

McLeod, J., \& Mackrill, T. (2018). Philosophical, conceptual and ethical perspectives on working with goals in therapy. In M. Cooper \& D. Law (Eds.), Working with goals in psychotherapy and counselling.Oxford University Press.

Melin, J., Nordin, Å., Feldthusen, C., \& Danielsson, L. (2019). Goal setting in physiotherapy: Exploring a person-centered perspective. Physiotherapy Theory and Practice. https://doi.org/10.1080/ 09593985.2019.1655822.

Meyer, S. B., \& Lunnay, B. (2013). The application of abductive and retroductive inference for the design and analysis of theory-driven sociological research. Sociological Research Online, 18(1), 86.

Moore, E., Holding, A. C., Moore, A., Levine, S. L., Powers, T. A., Zuroff, D. C., \& Koestner, R. (2020). The role of goal-related autonomy: A self-determination theory analysis of perfectionism, poor goal progress, and depressive symptoms. Journal of Counseling Psychology.

Morgan, D. (2014). Pragmatism as a paradigm for social research. Qualitative Inquiry, 20(8), 1045.

Nahum, D., Alfonso, C. A., \& Sönmez, E. (2019). Common factors in psychotherapy. In Advances in psychiatry (pp. 471-481). Springer.
Oddli, H. W., McLeod, J., Nissen-Lie, H. A., Rønnestad, M. H., \& Halvorsen, M. S. (2021). Future orientation in successful therapies: Expanding the concept of goal in the working alliance. Journal of Clinical Psychology. https://doi.org/10.1002/jclp.23108.

Ong, W. T., Murphy, D., \& Joseph, S. (2020). Unnecessary and incompatible: A critical response to Cooper and McLeod's conceptualization of a pluralistic framework for person-centered therapy. Person-Centered \& Experiential Psychotherapies, 19(2), $168-182$.

Renger, S., \& Macaskill, A. (2021a). Simplifying the definition of the fully functioning person for client use. Counselling and Psychotherapy Research. https://doi.org/10.1002/capr.12386.

Renger, S., \& Macaskill, A. (2021b). Developing the foundations for a learning-based humanistic therapy. Journal of Humanistic Psychology. https://doi.org/10.1177/00221678211007668.

Renger, S., Macaskill, A., \& Naylor, B. (2020). Learning and change within person-centred therapy: Views of expert therapists. Counselling and Psychotherapy Research, 20(3), 535-544. https://doi. org/10.1002/capr.12291.

Rief, W. (2021). Moving from tradition-based to competence-based psychotherapy. Evidence-Based Mental Health. https://doi.org/10. 1136/ebmental-2020-300219.

Roch, R. M., Rösch, A. G., \& Schultheiss, O. C. (2017). Enhancing congruence between implicit motives and explicit goal commitments: Results of a randomized controlled trial. Frontiers in Psychology, 8, 1-16. https://doi.org/10.3389/fpsyg.2017.01540.

Rodgers, B. (2017). The trouble with numbers: Some fundamental flaws with using standardized outcome measures. Psychotherapy and Politics International. https://doi.org/10.1002/ppi.1423.

Rogers, C. R. (1969). Freedom to learn. Merrill.

Rogers, C. R. (1952). "Person-centered" Psychotherapy. Scientific American, 187(5), 66-75.

Rogers, C. R. (1967). Concept of fully functioning person. Humanitas, $3(2), 185-202$.

Sales, C., \& Alves, P. C. (2016). Patient-centered assessment in psychotherapy: A review of individualized tools. Clinical Psychology: Science and Practice, 23(3), 265-283. https://doi.org/10.1111/ cpsp. 12162.

Teddlie, C., \& Tashakkori, A. (2009). Foundations of mixed methods research: Integrating quantitative and qualitative approaches in the social and behavioral sciences. SAGE.

Tryon, G. S., Birch, S. E., \& Verkuilen, J. (2018). Meta-analyses of the relation of goal consensus and collaboration to psychotherapy outcome. Psychotherapy, 55(4), 372.

Publisher's Note Springer Nature remains neutral with regard to jurisdictional claims in published maps and institutional affiliations. 